\title{
Can risk assessment predict suicide in secondary mental healthcare? Findings from the South London and Maudsley NHS Foundation Trust Biomedical Research Centre (SLaM BRC) Case Register
}

\author{
Javier-David Lopez-Morinigo ${ }^{1,2} \cdot$ Andrea C. Fernandes $^{3} \cdot$ Hitesh Shetty $^{4} \cdot$ Rosa Ayesa-Arriola $^{5,6} \cdot$ Ashraful Bari $^{2}$. \\ Robert Stewart ${ }^{3,4} \cdot$ Rina Dutta ${ }^{3,4}$
}

Received: 29 December 2017 / Accepted: 28 March 2018 / Published online: 2 June 2018

(c) The Author(s) 2018

\begin{abstract}
Purpose The predictive value of suicide risk assessment in secondary mental healthcare remains unclear. This study aimed to investigate the extent to which clinical risk assessment ratings can predict suicide among people receiving secondary mental healthcare.

Methods Retrospective inception cohort study $(n=13,758)$ from the South London and Maudsley NHS Foundation Trust (SLaM) (London, UK) linked with national mortality data ( $n=81$ suicides). Cox regression models assessed survival from the last suicide risk assessment and ROC curves evaluated the performance of risk assessment total scores.

Results Hopelessness $(\mathrm{RR}=2.24,95 \% \mathrm{CI} 1.05-4.80, p=0.037)$ and having a significant loss $(\mathrm{RR}=1.91,95 \% \mathrm{CI} 1.03-3.55$, $p=0.041)$ were significantly associated with suicide in the multivariable Cox regression models. However, screening statistics for the best cut-off point (4-5) of the risk assessment total score were: sensitivity 0.65 (95\% CI 0.54-0.76), specificity 0.62 (95\% CI 0.62-0.63), positive predictive value 0.01 (95\% CI 0.01-0.01) and negative predictive value 0.99 (95\% CI 0.99-1.00).
\end{abstract}

Conclusions Although suicide was linked with hopelessness and having a significant loss, risk assessment performed poorly to predict such an uncommon outcome in a large case register of patients receiving secondary mental healthcare.

Keywords Suicide $\cdot$ Risk assessment $\cdot$ Secondary mental healthcare $\cdot$ Mental pain

\section{Introduction}

Javier-David Lopez-Morinigo and Andrea C. Fernandes contributed equally to this work and should be jointly acknowledged as first named authors.

Electronic supplementary material The online version of this article (https://doi.org/10.1007/s00127-018-1536-8) contains supplementary material, which is available to authorized users.

Javier-David Lopez-Morinigo

javier.lopez-morinigo@kcl.ac.uk

1 Department of Psychosis Studies, Institute of Psychiatry, Psychology and Neuroscience, King's College London, De Crespigny Park, PO Box 68, London SE5 8AF, UK

2 CAS Behavioural Health, London, UK

3 Department of Psychological Medicine, Institute of Psychiatry, Psychology and Neuroscience, King's College London, London, UK
Every year, almost one million people die from suicide across the world [1], which appears to have increased since the start of the 2007 economic recession [2]. Indeed, suicide represents one of the three leading causes of death in the most economically productive age group (15-44 years)

4 South London and Maudsley NHS Foundation Trust, London, UK

5 Department of Psychiatry, Marqués de Valdecilla University Hospital, IFIMAV, School of Medicine, University of Cantabria, Santander, Spain

6 Centro Investigación Biomédica en Red de Salud Mental (CIBERSAM), Madrid, Spain 
[3]. Of concern, suicide rates in the UK have shown no reduction over the past 5 years [4].

Up to $90 \%$ of people who complete suicide are found to have had a 'psychiatric disorder' [5], contributing to $47-74 \%$ of the population risk of suicide, with half of people completing suicide meeting retrospectively applied criteria for depression $[6,7]$. Although it could be envisaged that secondary mental health services may play a crucial role in 'suicide prevention' [8], over two-thirds of those who take their lives in the UK have not received secondary mental healthcare in the year before death [4].

Risk assessment in mental health services might conceivably help reduce suicide rates, and the UK Department of Health [9] and 2004 NICE guidelines [10] recommended the use of structured clinical risk assessments. However, completed suicide thankfully remains a very uncommon event, and two early studies warned of the high number of false positives picked up to detect the majority of suicides using this approach [11, 12]. In particular, even a hypothetical test with a sensitivity and specificity of $99 \%$ in a high-risk population (defined as a suicide rate of $250 / 100,000 /$ years) cannot predict suicide beyond a $20 \%$ level of efficiency [11]. Consistent with this, recent metaanalyses have concluded that risk scales have a limited role in predicting suicidal behaviour [13-15], although there are important issues of between-study heterogeneity [13]. In keeping with these meta-analyses, a 2017 multicentre study in the UK [16] replicated the limited use of risk scales to predict repeated self-harm, which is in line with our previous report on risk assessment and suicide by patients with schizophrenia spectrum disorders under secondary mental healthcare [17]. However, using risk assessment scales continues to be common clinical practice [18].

In addition, the extent to which risk assessment can predict suicide mortality (rather than 'self-harm', 'suicide attempts' or 'suicidal behaviour') in a large sample of mental health service users irrespective of diagnosis, which also changes over time [19], has not been examined to date. Within this context, we investigated the performance of all full suicide risk assessments from the South London and Maudsley (SLaM) Biomedical Research Centre (BRC) Case Register (in South-East London, UK) over 2007-2015 to predict suicide. Whilst anticipating that some risk factors would be statistically associated with a higher risk of suicide, namely previous suicide attempts, suicidal ideation, hopelessness, alcohol/drugs and impulsivity, we sought to clarify positive predictive values at different levels of raised risk, as well as the extent to which a risk assessment might allow clinicians to rule out risk: i.e., the extent to which 'low-risk' patients would not end their lives.

\section{Methods}

\section{Participants}

As stated, the sample was derived from the SLaM BRC Case Register. SLaM is one of Europe's largest mental health services, providing secondary mental healthcare to four boroughs in South-East London (UK): Lambeth, Southwark, Lewisham and Croydon. Approximately, 1.23 million inhabitants reside in this geographic catchment area, which as a whole was found to be comparable with other populations of London in terms of age, gender, education and socio-economic status distributions $[20,21]$. Fully electronic health records have been in use across all SLaM services since 2006, and in 2007-2008, the Clinical Record Interactive Search (CRIS) system was built which renders de-identified copies of records available for research use with appropriate governance structures [20]. CRIS received ethical approval as an anonymised data resource for secondary analyses from the Oxford C Research Ethics Committee (reference: 08/H0606/71+5), and currently accesses data on over 300,000 patients [21]. The same research ethics approval also covers the pseudonymised linkage between CRIS data and those from the Office for National Statistics (ONS) in April 2015 [22], which registers all deaths in the UK and the official cause of death, including suicide and the method of suicide according to ICD-10 classification [23].

Those patients who had received SLaM care (i.e., had at least one face-to-face contact with a clinical member of staff) over the period from 1st January 2007 to 1st April 2015 and had at least one suicide risk assessment documented within the study period were included. Those who died from suicide within the study period were compared with those who did not. The analysis described here was based on a surveillance period from 1 January 2007 to 1 April 2015, the rationale being that the electronic clinical records coverage became complete across all SLaM services during 2006 and, at the time of the analysis, the last death certification linkage had been accomplished in the beginning of April 2015.

\section{Measures}

\section{Risk assessment}

'Full risk assessment' is a compulsory target across the Trust when 'high risk' is determined from a 'brief risk assessment', which is mandatory for all active cases. All patients who have been seen by a member of clinical staff have a 'brief risk assessment' documented, which is a 
narrative record of the patient's risk: (1) to one's self; (2) to others and (3) from others. If the patient is deemed at 'high' risk in any of these domains, a 'full risk assessment' needs to be completed and updated over time, which consists of a structured assessment taking the form of present/absent tick-boxes enquiring about widely recognised risk factors for three major clusters: suicide, violence and self-neglect. Full risk assessment is entered into CRIS as structured information separately from clinical freetext entries. Hence, information on those who had a 'full risk assessment' documented (compared to those without 'full risk assessment', including those with 'partial' risk assessment, i.e., only some items out of the 15-item full suicide risk assessment) can be reliably extracted from CRIS. For the purposes of this study, only those patients with a 'full suicide risk assessment' were included, that is, those patients with ratings on the 15 items included in the full suicide risk assessment, which is available in Appendix 1 (supplementary material available online). Positive responses can be summed to create total scores, i.e., the higher the score the greater the suicide risk, which yielded good internal consistency (Cronbach $\alpha$ coefficients of 0.69) [24]. The most recent full suicide risk assessment was considered for this study.

\section{Demographic and clinical covariates}

Demographic and clinical covariates included age at the time of risk assessment, gender, ethnicity, religion, marital status, employment status, social deprivation and ICD-10 diagnosis [23].

Social deprivation was scored through an anonymous link created in CRIS between lower super output area residence code of the latest permanent address (a geographic unit comprising approximately 400 households) and summary data for that area from 2007 UK Census output. Thus, the Index of Multiple Deprivation (IMD) is derived from seven domains: income, employment, health, education, housing and services, crime and environment [25].

ICD-10 diagnoses [23] were reached by consensus by the treating multidisciplinary team, including input from a senior consultant psychiatrist. Specifically, several clinically meaningful categories were created as follows: 'organic mental disorders' (F0), 'substance abuse' (F1), 'schizophrenia spectrum disorders' (F2), 'mood disorders' (F3), 'neurotic disorders' (F4) and 'all others' (F5-F7).

\section{Suicide method}

Suicide method was ascertained using death certificate [22] ICD-10 codes [23] and the following groups were used to define this: poisoning-X64; hanging -X70; drowning$\mathrm{X} 71$; cutting-X78; jumping (either from high place or in front of a vehicle)-X80, X81; suicide by unspecified means-X84; and undetermined cause of death-Y10-34. Those with an 'undetermined cause of death' code were considered as suicides, because in the UK most 'open verdicts' have been reported as very likely to be suicides [26].

\section{Statistical analysis}

First, for descriptive purposes, for all SLaM 'active' service users (i.e., at least one face-to-face contact with a staff member) over the study period (2007-2015), we investigated suicide rates differences between those with/without full risk assessment.

Second, in those with at least one full risk assessment documented (i.e., the study sample), risk assessment individual items and total scores, as independent variables, entered into Kaplan-Meier survival analyses and Cox regression models [27], respectively, to investigate associations with time to suicide. Proportional hazards assumptions were checked as standard for Cox procedures and no evidence of violation was found, i.e., the survival curves for two strata (determined by the values for the covariates) had 'hazard' functions, which were 'proportional' (or constant) over time. Age, gender, religion, employment and marital status, ethnic group, IMD and primary psychiatric diagnosis were entered as covariates. For the survival analyses, the follow-up period began at the time of the last risk assessment and the end date was the date of death (including suicide) or the censoring point (last face-to-face contact, date of death from nonsuicide causes or 1st April 2015, whichever came sooner).

In addition, receiver operating characteristic (ROC) curves [28], which compare the true positive rate (i.e., sensitivity) with the false positive rate (i.e., ' 1 -specificity') at different cut-off points for the parameter (risk assessment total score in our study), were plotted to analyse the performance of risk assessment total scores to predict suicide. In particular, sensitivity, specificity, positive and negative predictive values, the area under the curve (AUC), likelihood ratios (positive and negative) and diagnostic odds ratio (OR) were investigated for the best cut-off point, including 95\% confidence intervals (CI) for each statistic at each risk assessment total score. Positive and negative predictive values are the probability that subjects with a positive (high risk) result will truly have the outcome of interest (in this study, death from suicide), and the probability that subjects with a negative (low risk) result will not have such an outcome, respectively. The AUC is a measure of how well risk assessment total score can distinguish those who will die from suicide from those who will not. Likelihood ratios are the likelihood that a given test result would be expected in a patient who took his/her life compared to the likelihood that same result would be expected in a patient who did not end his/her life. Diagnostic ORs are the ratio of the odds of 
the test being positive (high risk) if the subject ended his/ her life relative to the odds of the test being positive if the subject did not die from suicide.

A significant level of 5\% (two-tailed) was set for all the above analyses, which were performed using the statistical package R (version 3.20) [29].

\section{Results}

\section{Study sample}

Over 2007-2015, there were 99,507 SLaM 'active' cases, i.e., those who had at least one face-to-face contact with a SLaM staff member over that period (2007-2015), of whom 358 were ascertained as having died by suicide. Of all these active SLaM service users, 13,758 subjects had all suicide-related items completed on a full risk assessment, and a further 1409 had incomplete data (with at least one item rated). Of the 13,758 individuals, who formed the study sample, 81 were recorded as having died by suicide. Taking into account the observation time of each patient, the analysed sample contributed to 80,769.17 person-years, which yielded a suicide rate of 100.28/100,000 person-years. In those with a partial risk assessment $(n=1409)$, the suicide rate was $51.60 / 100,000$ person-years, while for those with no risk assessment completed $(n=80,340)$, the suicide rate was $88.34 / 100,000$ person-years. These differences were not statistically significant $\left(X^{2}=6, d f=4, p=0.19\right)$.

The baseline demographic and clinical characteristics of the sample $(n=13,758)$ and differences between those who took their lives and those who did not are presented in Table 1. Although there was a higher male predominance in the suicide completers group than in those who did not end their lives $(\mathrm{OR}=1.67,95 \% \mathrm{CI} 1.04-2.69, p=0.03)$, no further significant differences emerged in age at first presentation, religion, marital status, ethnicity, living status, employment, social deprivation, first language (English vs. all others) and ICD-10 diagnoses. Hanging was the most common suicide method $(n=28)$. Twenty-one subjects received an undetermined cause of death. There were no suicides by firearms.
Table 1 Demographics and clinical characteristics of the sample

\begin{tabular}{|c|c|c|c|c|}
\hline & $\begin{array}{l}\text { Suicides } \\
N=81\end{array}$ & $\begin{array}{l}\text { Non-suicides } \\
N=13,678\end{array}$ & & $p$ value \\
\hline & Mean \pm SD & Mean \pm SD & & \\
\hline Age at risk assessment (years) & $41.3 \pm 12.2$ & $40.6 \pm 11.5$ & & 0.60 \\
\hline Social deprivation & $\begin{array}{l}28.6 \pm 13.4 \\
n(\%)\end{array}$ & $\begin{array}{l}28.6 \pm 12.3 \\
n(\%)\end{array}$ & OR (95\% CI) & 0.98 \\
\hline Gender (males) & $56(69.1)$ & $7823(57.2)$ & $1.67(1.04-2.69)$ & 0.03 \\
\hline Marital status (unmarried) & $72(88.9)$ & $11,909(87.1)$ & $1.10(0.55-2.21)$ & 0.78 \\
\hline Employment status (unemployed) & $30(37.0)$ & $4662(34.0)$ & $1.57(0.48-5.14)$ & 0.46 \\
\hline Living status (alone) & $19(23.5)$ & $3093(22.6)$ & $1.04(0.57-1.89)$ & 0.90 \\
\hline Religion (yes) & $20(24.7)$ & $3177(23.2)$ & $1.00(0.60-1.67)$ & 0.98 \\
\hline \multicolumn{5}{|l|}{ Ethnicity } \\
\hline White & $50(61.7)$ & $6916(50.6)$ & $1.85(1.02-3.35)$ & 0.04 \\
\hline Black & $14(17.3)$ & $3525(25.8)$ & Ref. & \\
\hline Others & $17(21.0)$ & $3237(23.7)$ & $1.37(0.67-2.78)$ & 0.38 \\
\hline First language (non-English) & $40(49.4)$ & $5971(43.7)$ & $1.53(0.99-2.37)$ & 0.06 \\
\hline \multicolumn{5}{|l|}{ Diagnosis } \\
\hline Organic disorders & $1(23.0)$ & $270(2.0)$ & Ref. & \\
\hline Substance use disorders & $10(12.3)$ & $1232(9.00)$ & $1.95(0.25-15.2)$ & 0.53 \\
\hline Schizophrenia spectrum & $31(38.3)$ & $5713(41.8)$ & $1.28(0.17-9.34)$ & 0.81 \\
\hline Mood disorders & $24(26.6)$ & $2643(19.3)$ & $2.28(0.30-16.9)$ & 0.42 \\
\hline Neurotic disorders & $5(6.17)$ & $860(6.30)$ & $1.60(0.19-13.7)$ & 0.67 \\
\hline Other diagnoses & $10(12.3)$ & 2960 (21.6) & $0.85(0.10-6.60)$ & 0.87 \\
\hline \multicolumn{5}{|l|}{ Method } \\
\hline Hanging & $28(34.6)$ & & & \\
\hline Intoxication & $6(7.4)$ & & & \\
\hline Jumping & $3(3.7)$ & & & \\
\hline Unspecified means & $16(19.7)$ & & & \\
\hline NA & $7(8.6)$ & & & \\
\hline Undetermined cause of death & $21(25.9)$ & & & \\
\hline
\end{tabular}


Table 2 Unadjusted univariate analyses: risk assessment items

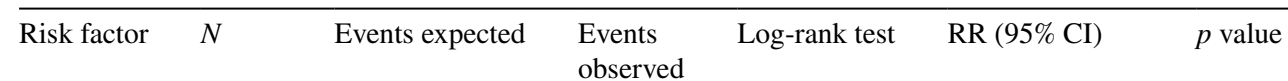

\section{Previous suicide attempts}

Present $\quad 5657 \quad 33$

Violent method

$\begin{array}{llll}\text { Absent } & 9167 & 50.7 & 37 \\ \text { Present } & 3069 & 17.3 & 31\end{array}$

Plan to end life

$\begin{array}{lrll}\text { Absent } & 11,551 & 64.5 & 53 \\ \text { Present } & 1258 & 6.5 & 18\end{array}$

Suicidal ideation

$\begin{array}{lrrr}\text { Absent } & 10,583 & 61.7 & 5 \\ \text { Present } & 2843 & 15.3 & 26 \\ \text { Hopelessness } & & & \end{array}$

Hopelessness

$\begin{array}{llll}\text { Absent } & 9419 \quad 55.1 & 37\end{array}$

$\begin{array}{llll}\text { Present } & 3811 & 20.9 & 39\end{array}$

Distress

Absent $\quad 8617 \quad 51.5 \quad 42$

$\begin{array}{llll}\text { Present } & 4651 & 26.5 & 36\end{array}$

No control over life

$\begin{array}{llll}\text { Absent } & 9290 & 55.1 & 4 \\ \text { Present } & 3576 & 20.9 & 34\end{array}$

Alcohol/drugs

$\begin{array}{llll}\text { Absent } & 7834 & 44.1 & 36\end{array}$

$\begin{array}{llll}\text { Present } & 4971 & 27.9 & 36\end{array}$

Impulsivity

Absent $\quad 7292 \quad 43.5$

Present $\quad 5636 \quad 33.5$

Living alone

Absent $\quad 8358 \quad 48.3$

Present $\quad 4949 \quad 30.7$

Poor physical health

$\begin{array}{llll}\text { Absent } & 9616 & 56.2 & 56 \\ \text { Present } & 3431 & 20.8\end{array}$

Significant loss

Absent $\quad 8243 \quad 50 \quad 39$

Present $4256 \quad 24$

Disengagement

$\begin{array}{lll}\text { Absent } & 9841 & 58.3 \\ \text { Present } & 3277 & 19.7\end{array}$

Recent hospital discharge

\begin{tabular}{lrlrlll} 
Absent & 10,973 & 65.1 & 56 & 7.3 & $1.93(1.20-3.14)$ & 0.007 \\
Present & 2399 & 13.9 & 23 & & & \\
Family history & & & & & $0.46(0.11-1.90)$ & 0.268 \\
Absent & 5921 & 32.88 & 35 & 1.2 & & \\
Present & 730 & 4.12 & 2 & & \\
\hline
\end{tabular}

$1.60(0.99-2.51)$

0.051

.2

8




\section{Risk assessment factors}

Differences in individual risk assessment items between suicide completers and non-completers (Kaplan-Meier survival analyses) are presented in Table 2. The following items were significantly associated with an increased risk of suicide: previous suicide attempts $(\mathrm{RR}=2.46,95 \% \mathrm{CI}$ $1.51-4.01, p<0.001)$, previous use of a violent method $(\mathrm{RR}=2.46,95 \% \mathrm{CI} 1.53-3.97, p<0.001)$, plans to end life $(\mathrm{RR}=3.37,95 \%$ CI $1.98-5.77, p<0.001)$, suicidal ideation $(\mathrm{RR}=2.06,95 \% \mathrm{CI} 1.30-3.31, p=0.002)$, hopelessness ( $\mathrm{RR}=2.79,95 \%$ CI $1.78-4.37, p<0.001)$, distress $(\mathrm{RR}=1.66,95 \% \mathrm{CI} 1.07-2.60, p=0.024)$, lack of control over life $(\mathrm{RR}=2.13,95 \%$ CI $1.36-3.35, p<0.001)$, impulsivity ( $\mathrm{RR}=1.6495 \% \mathrm{CI} 1.05-2.57, p=0.030)$, having a significant loss ( $R R=1.88,95 \%$ CI $1.20-2.96$, $p=0.006)$, disengagement $(\mathrm{RR}=1.85,95 \% \mathrm{CI} 1.17-2.91$, $p=0.007)$ and recent hospital discharge $(\mathrm{RR}=1.93,95 \%$ CI $1.20-3.14, p=0.007$ ).

Cox regression analyses of the relationship between those risk assessment factors significantly associated with risk of suicide (see Table 2) are presented in Table 3. The left column shows the results only after adjusting the analyses for gender, which had been the only significant baseline characteristic associated with suicide risk (see Table 1). All the risk factors remained significant (Table 3, left column). The right column of Table 3 presents coefficients from a model containing all factors; in this, only hopelessness ( $R R=2.24,95 \%$ CI $1.05-4.80$, $p=0.037)$ and having a significant loss $(\mathrm{RR}=1.91,95 \%$ CI $1.03-3.55, p=0.041)$ remained statistically significant predictors of suicide. All the other associations, apart from that with previous suicide attempts (which showed a

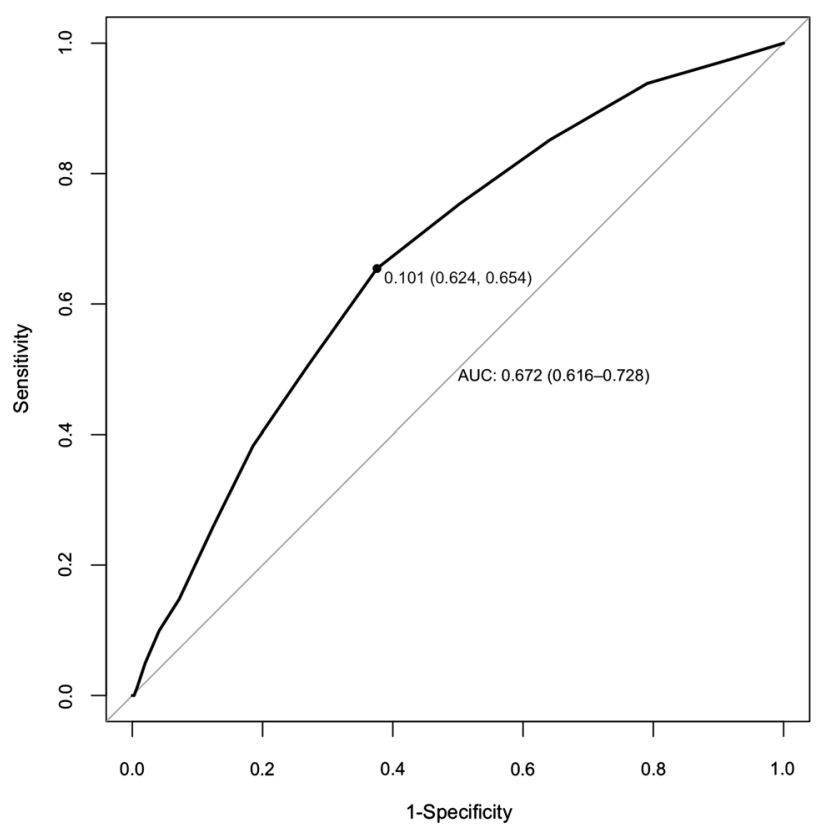

Fig. 1 ROC curve for risk assessment total scores

strengthened coefficient but wider confidence intervals), were substantially attenuated.

\section{Risk assessment overall performance}

The diagnostic accuracy statistics (and 95\% CI) for each risk assessment total score are detailed in Table 4. ROC curve analyses for risk assessment total scores, which are shown in Fig. 1, found the optimal cut-off point to be 4-5 (above which the risk would be 'high'; below which the risk would
Table 3 Adjusted Cox regression analyses: risk assessment items

\begin{tabular}{llrrc}
\hline Individual items & $\mathrm{RR}^{\mathrm{a}}(95 \% \mathrm{CI})$ & $p$ value & $\mathrm{RR}^{\mathrm{b}}(95 \% \mathrm{CI})$ & $p$ value \\
\hline Gender (male) & $1.67(1.04-2.67)$ & 0.03 & $1.70(0.95-3.02)$ & 0.077 \\
Suicidal history & $\mathbf{1 . 6 7}(\mathbf{1 . 0 4}-\mathbf{2 . 6 7})$ & $<\mathbf{0 . 0 0 1}$ & $2.00(0.89-4.53)$ & 0.094 \\
Violent method & $\mathbf{2 . 5 8}(\mathbf{1 . 5 8}-\mathbf{4 . 2 1})$ & $<\mathbf{0 . 0 0 1}$ & $1.31(0.65-2.65)$ & 0.453 \\
Plan to end life & $\mathbf{2 . 4 7}(\mathbf{1 . 5 3}-\mathbf{3 . 9 8})$ & $<\mathbf{0 . 0 0 1}$ & $1.20(0.54-2.63)$ & 0.657 \\
Suicidal ideation & $\mathbf{2 . 1 3}(\mathbf{1 . 3 2}-\mathbf{3 . 4 1})$ & $\mathbf{0 . 0 0 2}$ & $0.82(0.40-1.67)$ & 0.577 \\
Hopelessness & $\mathbf{2 . 9 0}(\mathbf{0 . 8 5}-\mathbf{4 . 5 5})$ & $<\mathbf{0 . 0 0 1}$ & $\mathbf{2 . 2 4}(\mathbf{1 . 0 5}-\mathbf{4 . 8 0})$ & $\mathbf{0 . 0 3 7}$ \\
Distress & $\mathbf{1 . 7 2}(\mathbf{1 . 1 0 - 2 . 7 0})$ & $\mathbf{0 . 0 2 0}$ & $0.90(0.48-1.68)$ & 0.746 \\
No control over life & $\mathbf{2 . 2 1}(\mathbf{1 . 4 0 - 3 . 4 8})$ & $<\mathbf{0 . 0 0 1}$ & $0.95(0.47-1.91)$ & 0.881 \\
Impulsivity & $\mathbf{1 . 6 5}(\mathbf{1 . 0 5}-\mathbf{2 . 5 8})$ & $\mathbf{0 . 0 2 9}$ & $1.05(0.56-1.97)$ & 0.875 \\
Significant loss & $\mathbf{1 . 9 5}(\mathbf{1 . 2 3}-\mathbf{3 . 0 7})$ & $\mathbf{0 . 0 0 4}$ & $\mathbf{1 . 9 1}(\mathbf{1 . 0 3}-\mathbf{3 . 5 5})$ & $\mathbf{0 . 0 4 1}$ \\
Disengagement & $\mathbf{1 . 8 5}(\mathbf{1 . 1 7 - 2 . 9 2})$ & $\mathbf{0 . 0 0 8}$ & $1.16(0.61-2.20)$ & 0.653 \\
Recent hospital discharge & $\mathbf{1 . 9 7}(\mathbf{1 . 2 1}-\mathbf{3 . 2 1})$ & $\mathbf{0 . 0 0 6}$ & $1.45(0.77-2.74)$ & 0.247 \\
\hline
\end{tabular}

Bold values indicate statistically significance $p<0.05$

${ }^{a}$ Analysis adjusted for gender only

${ }^{\mathrm{b}}$ Fully adjusted analysis 
Table 4 Risk assessment total scores (number of risk factors present) and diagnostic accuracy statistics with $95 \%$ confidence intervals

\begin{tabular}{|c|c|c|c|c|c|c|c|c|c|}
\hline $\begin{array}{l}\text { Risk assess- } \\
\text { ment (Total } \\
\text { score) }\end{array}$ & Suicides & Non-suicides & $\begin{array}{l}\text { Sensitivity, } \\
\%(95 \% \mathrm{CI})\end{array}$ & $\begin{array}{l}\text { Specificity, } \\
\%(95 \% \mathrm{CI})\end{array}$ & $\begin{array}{l}\text { Positive pre- } \\
\text { dictive value, } \\
\%(95 \% \mathrm{CI})\end{array}$ & $\begin{array}{l}\text { Negative } \\
\text { predictive } \\
\text { value, } \% \\
(95 \% \mathrm{CI})\end{array}$ & $\begin{array}{l}\text { Likelihood } \\
\text { ratio, + }(95 \% \\
\mathrm{CI})\end{array}$ & $\begin{array}{l}\text { Likelihood } \\
\text { ratio, - }(95 \% \\
\text { CI })\end{array}$ & $\begin{array}{l}\text { Diagnostic } \\
\text { OR }(95 \% \text { CI })\end{array}$ \\
\hline 0 & 2 & 1113 & $98(91-100)$ & $8(8-9)$ & $1(0-1)$ & $\begin{array}{l}100 \\
(99-100)\end{array}$ & $1.1(1.0-1.1)$ & $0.3(0.1-1.2)$ & $3.5(0.9-14.3)$ \\
\hline 1 & 3 & 1748 & $94(86-98)$ & $21(20-22)$ & $1(1-1)$ & $\begin{array}{l}100(100- \\
100)\end{array}$ & $1.2(1.1-1.3)$ & $0.3(0.1-0.7)$ & $4.0(1.6-9.9)$ \\
\hline 2 & 7 & 2042 & $85(76-92)$ & $36(35-37)$ & $1(1-1)$ & $\begin{array}{c}100(100- \\
100)\end{array}$ & $1.3(1.2-1.5)$ & $0.4(0.2-0.7)$ & $3.2(1.7-5.9)$ \\
\hline 3 & 8 & 1909 & $75(64-84)$ & $50(49-51)$ & $1(1-1)$ & $\begin{array}{c}100(100- \\
100)\end{array}$ & $1.5(1.3-1.7)$ & $0.5(0.3-0.7)$ & $3.02(1.8-5.0)$ \\
\hline 4 & 8 & 1727 & $65(54-76)$ & $62(62-63)$ & $1(1-1)$ & $\begin{array}{l}100 \\
(99-100)\end{array}$ & $1.7(1.5-2.0)$ & $0.5(0.4-0.7)$ & $3.1(2.0-5.0)$ \\
\hline 5 & 12 & 1443 & $51(39-62)$ & $73(72-74)$ & $1(1-1)$ & $\begin{array}{l}100 \\
(99-100)\end{array}$ & $1.9(1.5-2.3)$ & $0.7(0.5-0.8)$ & $2.8(1.8-4.3)$ \\
\hline 6 & 10 & 1161 & $38(28-50)$ & $81(81-82)$ & $1(1-2)$ & $\begin{array}{l}100 \\
(99-100)\end{array}$ & $2.1(1.6-2.7)$ & $0.8(0.6-0.9)$ & $2.7(1.73-4.3)$ \\
\hline 7 & 10 & 836 & $26(17-37)$ & $88(87-88)$ & $1(1-2)$ & $\begin{array}{l}100 \\
(99-100)\end{array}$ & $2.1(1.4-3.0)$ & $0.8(0.7-1.0)$ & $2.5(1.5-4.1)$ \\
\hline 8 & 9 & 712 & $15(8-24)$ & $93(92-93)$ & $1(1-2)$ & $\begin{array}{l}100 \\
(99-100)\end{array}$ & $2.0(1.2-3.5)$ & $0.9(0.8-1.0)$ & $2.23(1.2-4.1)$ \\
\hline 9 & 4 & 427 & $10(4-19)$ & $96(96-96)$ & $1(1-3)$ & $\begin{array}{l}100 \\
(99-100)\end{array}$ & $2.4(1.2-4.7)$ & $0.9(0.8-1.0)$ & $2.6(1.2-5.3)$ \\
\hline 10 & 4 & 291 & $5(1-12)$ & 98 (98-98) & $1(1-4)$ & $\begin{array}{l}100 \\
(99-100)\end{array}$ & $2.5(0.9-6.6)$ & $1.0(0.9-1.0)$ & $2.6(0.9-7.1)$ \\
\hline 11 & 3 & 167 & $1(0-7)$ & 99 (99-99) & $1(0-5)$ & $\begin{array}{l}100 \\
(99-100)\end{array}$ & $\begin{array}{c}1.7(0.2- \\
11.7)\end{array}$ & $1.0(1.0-1.0)$ & $1.6(0.2-12.1)$ \\
\hline 12 & 1 & 64 & $0(0-4)$ & $1(1-1)$ & $0(0-9)$ & 99 (99-100) & $0(0-0)$ & $1.0(1.0-1.0)$ & NA \\
\hline 13 & 0 & 28 & NA & NA & NA & NA & NA & NA & NA \\
\hline 14 & 0 & 10 & NA & NA & NA & NA & NA & NA & NA \\
\hline
\end{tabular}

be 'low'), with a sensitivity of 0.65 (95\% CI 0.65-0.76), specificity of 0.62 (95\% CI 0.62-0.63) and an AUC of 0.67 (95\% CI 0.62-0.73). The positive and negative predictive values were 0.01 (95\% CI $0.01-0.01)$ and 0.99 (95\% CI $0.99-1.00)$, respectively.

\section{Discussion}

\section{Main findings}

We drew data from a large case register of patients receiving secondary mental healthcare in a defined catchment area over a prolonged period (2007-2015) linked with national mortality data and we tested the extent to which structured risk assessment items (individual risk factors and overall scores) predicted suicide. First, as expected, we identified a high number of suicides in a population of patients in secondary mental healthcare (approximately 100.28/100,000 person-year), approximately tenfold higher than in the general population (10.9/100,000 person-year) [22]. Second, we found that although a number of risk factors were significantly associated with suicide in the bivariate analyses (namely, being male, previous suicide attempts, previous use of violent methods, plans to end life, suicidal ideation, distress, lack of control over life, impulsivity, disengagement from services/non-compliance with medication and recent hospital discharge), only hopelessness and having a significant loss remained independent and statistically significant predictors of suicide in the multivariable regression models. Third, overall risk assessment performed poorly to predict suicide in a large sample of mental health service users, which was in line with our expectations and recent literature [13-15].

\section{Comparison with previous literature}

Of relevance, we did not find a protective effect of completing suicide risk assessment on reducing suicide rates as previously suggested [10], which was in line with further reviews of the NICE guidelines [30]. It might seem intuitive to speculate that those patients with a risk assessment 
documented are deemed at a higher risk of suicide by the treating team and they are more likely to receive a higher level of input and caution in management. It remains unanswerable what may have happened if these 'high risk' individuals had not been administered a risk assessment and to research this would raise ethical issues. However, recording of risk assessment is, to some degree, circular and more likely in those patients who will be followed-up by mental health services [31]. In addition, risk assessment in this cohort may have been completed due to concerns raised regarding other clusters of risk, such as violence to others and/or self-neglect [24]. Moreover, risk assessment completion rates may have been affected by the patient's legal status in some cases, which was not evaluated in this study. For instance, those receiving care under restriction, hence subject to the UK Mental Health Act 1983 (amended 2007) [32] may be more likely to have a risk assessment documented. In this regard, our findings are of major relevance from a human rights perspective, since these individuals may have been 'forced' to undertake an assessment which appears to have a limited value, which would also go against the 2015 UK Code of Practice [33].

In terms of risk factors, we replicated the association of being male [1,34], previous suicide attempts [35], previous use of violent methods [5], plans to end life and suicidal ideation [36], hopelessness [37, 38], distress, lack of control over life and impulsivity [39], having a significant loss [40], disengagement from services/non-compliance with medication and recent hospital discharge [4] with suicide. Consistent with previous models of suicide [41, 42], only hopelessness and having a significant loss remained significant. However, it should be noted that childhood trauma, which was not evaluated by our risk assessment questionnaire, was found to have greater effects on suicidality than depression and related variables [43], hence it should become part of routine clinical suicide risk assessment.

Over four decades ago, hopelessness was defined as 'the cognitive element of negative expectations' [37], which was also demonstrated to be the strongest predictor of suicide in outpatients [38], and this we replicated in our results. Hence, our findings agree, in part, with Mann's diathesisstress model of suicide [42] regarding the role of hopelessness, although impulsivity [39] was not significantly associated with suicide in our cohort. It should be noted, however, that impulsivity, as measured by the SLaM risk assessment, might refer to a different construct. On the other hand, we did find that having a significant loss was a predictor of suicide independently of other factors, which, in addition to the role of hopelessness, was consistent with the classic theory of 'suicide as psychache' [41]. Of note, the conceptualization of suicide as the consequence of 'mental pain or psychache' has been recently reconsidered [44] in light of decades of relatively unsuccessful neurobiological research
[45] based on Mann's model of suicide [42]. Indeed, over $90 \%$ of suicide attempters report 'mental pain' [46], which is frequently the consequence of a bereavement [40], which is of particular concern after surviving the suicide of a love one [47]. Moreover, 'mental pain' appears to be a contributor to suicide independently of depression [48], which is in full agreement with our results. Indeed, the relationship between suicide and 'mental illness' (from a psychiatric perspective) may be weaker than previously thought, especially in Western countries [44]. In keeping with this, neither medication compliance nor (psychiatric) diagnosis were associated with suicide in our large cohort of mental health service users, which may provide further support for a non-medical approach to suicide [49]. Hence, those patients receiving secondary mental healthcare at risk of suicide may particularly benefit from psychological therapies, as recommended by the UK NICE guidelines for depression [50], although not frequently offered [51].

In addition, overall risk assessment showed poor predictive validity, which was unsurprising, given the rarity of the outcome. In particular, high sensitivity was reached at the price of low specificity (i.e., a very high number of false positives to identify most of suicides) and vice versa, i.e., reducing the number of false positives (high specificity) occurred at the expenses of too many false negatives (low sensitivity), thus preventing high-risk patients from care and treating 'healthy' people unnecessarily, which was in full agreement with early literature [11, 12].

In keeping with this, for the most optimal cut-off point (4-5), a very low positive predictive value (1\%) and very high negative predictive value (99\%) emerged from the analyses. In other words, in this 'low-risk' group (those with less than four risk factors), there would be still 20 suicides (approximately one quarter of those who ended their lives). On the other hand, 6988 individuals (50.8\% of the total sample) would be classified as 'high-risk' patients, although only 61 of these subjects took their lives. The question arises. Is it, therefore, worth managing so many patients as 'suicidal' to prevent a few deaths? More specifically, in times of financial constraints, should so many patients receive high levels of care such as unnecessary admissions to hospital?

These findings were consistent with a 2017 literature review on 'the limitations of epistemic uncertainty' with regard to risk assessment, whose overall poor performance appears to be due to the so-called 'aleatory uncertainty'. In short, risk factors change 'by chance', which is unpredictable [18]. The concept of risk, therefore, requires a reformulation. Specifically, while suicide risk does not appear to be predictable, a more prevention-orientated approach may result in better clinical outcomes [52].

However, our findings concerning the association of hopelessness and having a significant loss with suicide, which as a whole provide some support for the 'mental pain' 
model of suicide [41], which was discussed above, still suggest that suicide may still be, to some degree, predictable.

\section{Future research}

While we do recommend that risk assessment should remain part of our routine clinical practice, a more narrative (free-text) approach should be taken [53] to better capture aspects such as 'mental pain', which, based on our findings, seems to be more useful in terms of clinical risk assessment. In particular, rather than categorising patients as 'low-medium-high' risk, the wide range of contributing factors to risk should be detailed in relation to the individual's mental health problems and the social context and how these factors may change dynamically over time, thus increasing or decreasing risk for a given individual, which is what matters clinically [52]. Patient information from electronic records can be easily, safely and securely de-identified to generate large datasets for secondary research [54], such as the SLaM CRIS [20, 21]. Specifically, naturalistic language processing (NLP) tools appear to be promising research instruments to extract statistically analysable clinical information from narrative electronic records, hence determining risk from free-text notes [55]. NLP techniques may assess suicide risk using information from unstructured questions with higher precision than the classic risk assessment scales [56], thus potentially capturing the presence of 'mental pain'.

Specifically, future studies should examine whether risk assessment changes over time, particularly self-ratings shortly before suicide may increase the predictive value of risk assessment. In this regard, mobile phone and web-based text messaging may represent a useful tool to self-monitor suicide risk [57], particularly to follow-up people attempting suicide [58] and to assess risk shortly before suicidal events, including suicides. For instance, the classic suicide note may have been substituted by a message left on this new media, which clinicians should discuss with patients and carers when assessing self-harm [59]. In addition, freetext-based risk assessment, which can be researched through NLP techniques [55], may be more accurate than psychometric scales [56]. Future research should, therefore, switch the focus from long-term risk factors to short-term risk algorithms, which are more relevant to the clinician [60]. However, the evidence of the use of communication technologies in health care and public health, which is known as mobile health (mHealth) [61], on suicide prevention is limited [62].

\section{Strengths and limitations}

The use of a large case register linked with national mortality data allowed us to investigate the role of risk assessment in predicting suicide in a large sample of patients who were receiving secondary mental healthcare within a defined geographic catchment and time period. Since most people living in South-East London requiring secondary mental healthcare receive this from NHS resources, our sample is likely to be representative. In addition, participants were followed-up for up to 9 years and, in addition to risk assessment ratings, a number of covariates were taken into account.

However, the study has some limitations to be borne in mind when drawing conclusions from the results. First, all participants were mental health service users residing in South-East London, which is an inner urban area. Hence, our findings may not generalise to people with mental health problems under primary care or those who live in rural areas. Second, the vast majority of SLaM patients (almost 90\%) did not have a structured risk assessment completed and those who did may have been deemed 'at-high-risk' by their treating teams. In other words, it could be still speculated that assessing risk in all patients receiving care may reduce risk. Third, although only the last suicide risk assessment was considered, risk factors may have changed from the time of risk assessment to death. Also, risk assessment scores may have been affected by survival, hence those who survived for longer (and therefore received care for a more prolonged period of time) may have been rated differently. Finally, other factors such as patient's legal status at the time of risk assessment or a history of childhood trauma, which were not evaluated in this study, may have affected both risk assessment completion rates and ratings, and the main outcome measure of this study, namely suicide.

\section{Implications and conclusions}

Our results, therefore, support the notion that neither individual risk factors nor a combination of them, i.e., risk assessment, can adequately predict suicide in a population of patients receiving mental healthcare. Suicide is a very uncommon outcome even in a high-risk group such as patients receiving secondary mental healthcare. Our study suggests that risk assessment cannot predict suicide in the clinical setting due to its very low occurrence, which is in full agreement with recent meta-analyses [13-15], although hopelessness and having a significant loss were linked with suicide, consistent with the classic 'mental pain' model of suicide $[41,44,46,48]$.

Meanwhile, further research on suicide prevention [62-64] is warranted. In particular, means restriction remains the first-line strategy to prevent both high-risk groups such as patients receiving mental healthcare [17] and the general population [65] from suicide.

Acknowledgements We are extremely grateful to all the patients who received care under the SLaM teams within the study period and the SLaM staff who, therefore, took part in this research project. 
Funding The development of the SLaM BRC Case Register was funded by two Capital Awards from the UK National Institute for Health Research and is further supported through the BRC Nucleus funded jointly by the Guy's and St Thomas' Trustees and South London and Maudsley Special Trustees. JDLM was funded by the British Medical Association via the Margaret Temple Research Award for Schizophrenia. RD is funded by a Clinician Scientist Fellowship awarded by the Academy of Medical Sciences in partnership with The Health Foundation. JDLM, ACF, HS, RB and RD are part-funded by the National Institute for Health Research (NIHR) Biomedical Research Centre and Dementia Biomedical Research Unit at South London and Maudsley NHS Foundation Trust and King's College London. JDLM and AB also acknowledge funding support from CAS Behavioural Health. The funders had no role in hypothesis generation, study design, data collection and analysis, decision to publish or the manuscript writing.

\section{Compliance with ethical standards}

Conflict of interest The authors disclosed no competing interests concerning the subject of the study.

Ethical statement This study was performed in accordance with the ethical standards laid down in the 1964 Declaration of Helsinki and its later amendments. Under UK law anonymised data can be used without prior consent and data for this study came from CRIS (see "Methods" section for details), which received ethical approval as an anonymised data resource for secondary analyses from the Oxford C Research Ethics Committee (reference: 08/H0606/71+5).

Open Access This article is distributed under the terms of the Creative Commons Attribution 4.0 International License (http://creativeco mmons.org/licenses/by/4.0/), which permits unrestricted use, distribution, and reproduction in any medium, provided you give appropriate credit to the original author(s) and the source, provide a link to the Creative Commons license, and indicate if changes were made.

\section{References}

1. World Health Organization (WHO) (2014) Preventing suicide: a global imperative. World Health Organization, Geneva

2. Oyesanya M, Lopez-Morinigo J, Dutta R (2015) Systematic review of suicide in economic recession. World J Psychiatry 5:243-254

3. Patton GC, Coffey C, Sawyer SM et al (2009) Global patterns of mortality in young people: a systematic analysis of population health data. Lancet 374:881-892

4. The National Confidential Inquiry into Suicide and Homicide by People with Mental Illness (2016) (NCISH) Annual Report: England, Northern Ireland, Scotland and Wales. October 2017. University of Manchester

5. Arsenault-Lapierre G, Kim C, Turecki G (2004) Psychiatric diagnoses in 3275 suicides: a meta-analysis. BMC Psychiatry 4:37

6. Cavanagh JT, Carson AJ, Sharpe M, Lawrie SM (2003) Psychological autopsy studies of suicide: a systematic review. Psychol Med 33:395-405

7. Hawton K, Harris L, Hall S, Smikin S, Bale E, Bond A (2003) Deliberate self-harm in Oxford, 1990-2000: a time of change in patient characteristics. Psychol Med 33:987-995

8. World Health Organization (WHO) (2013) Public health action for the prevention of suicide. World Health Organization, Geneva
9. Department of Health (DoH) and Social Security (1984) The management of deliberate self-harm. HMSO, London

10. National Institute for Health and Clinical Excellence (NICE) (2004) Clinical Guidance 16 Self-harm. https://www.nice.org. uk/Guidance/CG16. Accessed 7 Sep 2017

11. MacKinnon DR, Farberow NL (1976) An assessment of the utility of suicide prediction. Suicide Life Threat Behav 6:86-91

12. Pokorny AD (1983) Prediction of suicide in psychiatric patients. Arch Gen Psychiatry 40:249-257

13. Large M, Kaneson M, Myles N, Myles H, Gunaratne P, Ryan C (2016) Meta-analysis of longitudinal cohort studies of suicide risk assessment among psychiatric patients: heterogenity in results and lack of improvement over time. PLoS One 11:e0156322

14. Quinlivan L, Cooper J, Davies L, Hawton K, Gunnell D, Kapur N (2016) Which are the most useful scales for predicting repeat selfharm? A systematic review evaluating risk scales using measures of diagnostic accuracy. BMJ Open 6:e009297

15. Carter G, Milner A, McGill K, Pirkis J, Kapur N, Spittal M (2017) Predicting suicidal behaviours using clinical instruments: systematic review and meta-analysis of positive predictive values for risk scales. Br J Psychiatry 210:387-395

16. Quinlivan L, Cooper J, Meehan D et al (2017) Predictive accuracy of risk scales following self-harm: multicentre, prospective cohort study. Br J Psychiatry 210:429-436

17. Lopez-Morinigo JD, Ayesa-Arriola R, Torres-Romano B et al (2016) Risk assessment and suicide by patients with schizophrenia in secondary mental healthcare: a case-control study. BMJ Open 6:e011929

18. Large M, Galletly C, Myles N, Ryan CJ, Myles H (2017) Known unknowns and unknown unknowns in suicide risk assessment: evidence from meta-analyses of aleatory and epistemic uncertainty. Br J Psychiatry Bull 41:160-163

19. Heslin M, Lomas B, Lappin JM et al (2015) Diagnostic change 10 years after a first episode of psychosis. Psychol Med 45:2757-2769

20. Stewart R, Soremekun M, Perera G et al (2009) The South London and Maudsley NHS Foundation Trust Biomedical Research Centre (SLAM BRC) case register: development and descriptive data. BMC Psychiatry 9:51

21. Perera G, Broadbent M, Callard F et al (2016) Cohort profile of the South London and Maudsley NHS Foundation Trust Biomedical Research Centre (SLaM BRC) Case Register: current status and recent enhancement of an Electronic Mental Health Recordderived data resource. BMJ Open 6:e008721

22. Office for National Statistics (ONS) (2015) Suicide statistics: deaths registered in England and Wales. http://www.ons.gov. uk/ons/datasets-andtables/index $\cdot$ html? pageSize $=50 \&$ sortB $\mathrm{y}=$ none $\&$ sortDirection $=$ none $\&$ newquery $=$ suicide $\&$ content type $=$ Reference + table $\&$ content-type $=$ Dataset. Accessed $1 \mathrm{Apr}$ 2015

23. World Health Organization (WHO), The ICD-10 (1993) Classification of mental and behavioural disorders: diagnostic criteria for research. World Health Organization, Geneva

24. Wu CY, Chang CK, Hayes M, Broadbent M, Hotopf M, Stewart R (2012) Clinical risk assessment rating and all-cause mortality in secondary mental healthcare: the South London and Maudsley NHS Foundation Trust Biomedical Research Centre (SLAM BRC) Case Register. Psychol Med 42:1581-1590

25. Office for National Statistics (ONS) (2007) Indices of deprivation 2007 for super output areas. http://www.neighbourhood. statistics.gov.uk/dissemination/instanceSelection.do?JSAll owed $=$ true $\&$ Function $=\& \% 24 \mathrm{ph}=60 \_61 \&$ CurrentPag $\mathrm{eId}=61 \&$ step $=2 \&$ datas etFamilyId $=1893 \&$ instanceSelecti on $=122838 \&$ Next. $x=19 \&$ Next. $y=17$. Accessed 10 Oct 2009

26. Linsley KR, Schapira K, Kelly TP (2001) Open verdict v. suicide-importance to research. Br J Psychiatry 178:465-468 
27. Cox D (1972) Regression models and life tables (with discussions). J R Stat Soc 34:187-220

28. Hanley JA, McNeil BJ (1982) The meaning and use of the area under a receiver operating characteristic (ROC) curve. Radiology 143:29-36

29. R Core Team (2015) A language and environment for statistical computing. R Foundation for Statistical Computing

30. National Institute for Health and Clinical Excellence (NICE) (2011) Clinical guidance 133 self-harm. https://www.nice.org. uk/donotdo/do-not-use-risk-assessment-tools-and-scales-to-deter mine-who-should-and-should-not-be-offered-treatment-or-whoshould-be-discharged. Accessed 3 Sep 2017

31. Kapur N, Murphy E, Cooper J et al (2008) Psychosocial assessment following self-harm: results from the multi-centre monitoring of self-harm project. J Affect Disord 106:285-293

32. Department of Health (DoH) (2008) Mental Health Act 2007: patients on aftercare under supervision (ACUS): transitional arrangements. Department of Health, London

33. Department of Health (DoH) (2008) Code of practice: Mental Health Act 1983. TSO (The Stationer Office)

34. Hawton K, van Heeringen K (2009) Suicide. Lancet 373:1372-1381

35. Coryell W, Young EA (2005) Clinical predictors of suicide in primary major depressive disorder. J Clin Psychiatry 66:412-417

36. Bebbington PE, Minot S, Cooper C et al (2010) Suicidal ideation, self-harm and attempted suicide: results from the British psychiatric morbidity survey 2000. Eur Psychiatry 25:427-431

37. Minkoff K, Bergman E, Beck AT, Beck R (1973) Hopelessness, depression, and attempted suicide. Am J Psychiatry 30:455-459

38. Beck AT, Brown G, Berchick RJ, Stewart BL, Steer RA (1990) Relationship between hopelessness and ultimate suicide: a replication with psychiatric outpatients. Am J Psychiatry 147(2):190-195

39. Baca-Garcia E, Diaz-Sastre C, Garcia-Resa E et al (2005) Suicide attempts and impulsivity. Eur Arch Psychiatry Clin Neurosci 255:152-156

40. Guldin MB, Ina Siegismund Kjaersgaard M, Fenger-Grøn M et al (2017) Risk of suicide, deliberate self-harm and psychiatric illness after the loss of a close relative: a nationwide cohort study. World Psychiatry 16:193-199

41. Shneidman ES (1993) Suicide as psychache. J Nerv Ment Dis 181:145-147

42. Mann JJ, Waternaux C, Haas GL, Malone KM (1999) Toward a clinical model of suicidal behavior in psychiatric patients. Am J Psychiatry 156:181-189

43. Read J, Agar K, Barker-Collo S (2001) Assessing suicidality in adults: integrating childhood trauma as a major risk factor. Prof Psychol Res Pract 32:367-372

44. de Leon J, Baca-García E, Blasco-Fontecilla H (2015) From the serotonin model of suicide to a mental pain model of suicide. Psychother Psychosom 84:323-329

45. Mann JJ (2003) Neurobiology of suicidal behaviour. Nat Rev Neurosci 4:819-828

46. Blasco-Fontecilla H, Baca-Garcia E, Courtet P, Garcia Nieto R, de Leon J (2015) Horror vacui: emptiness might distinguish between major suicide repeaters and nonmajor suicide repeaters: a pilot study. Psychother Psychosom 84:117-119

47. Pompili M, Shrivastava A, Serafini G et al (2013) Bereavement after the suicide of a significant other. Indian J Psychiatry 55:256-263

48. Verrocchio MC, Carrozzino D, Marchetti D et al (2016) Mental pain and suicide: a systematic review of the literature. Front Psychiatry $7: 108$
49. Shahtahmasebi S (2013) Examining the claim that $80-90 \%$ of suicide cases had depression. Front Public Health 1:62

50. National Institute of Care and Clinical Excellence (2016) Depression in adults: recognition and management. Clinical guideline [cg90]. https://www.nice.org.uk/guidance/cg90

51. Geekie J, Read J, Renton J, Harrop C (2017) Do English mental health services know whether they followed N.I.C.E. guidelines with patients who killed themselves? Psychol Psychother Theory Res Pract 90:797-800

52. Pisani AR, Murrie DC, Silverman MM (2016) Reformulating suicide risk formulation: from prediction to prevention. Acad Psychiatry 40:623-629

53. Carroll R, Metcalfe C, Steeg S et al (2016) Psychosocial assessment of self-harm patients and risk of repeat presentation: an instrumental variable analysis using time of hospital presentation. PLoS One 11(2):e0149713

54. Fernandes AC, Cloete D, Broadbent MT et al (2013) Development and evaluation of a de-identification procedure for a case register coursed from mental health electronic records. BMC Med Inform Decis Mak 13:71

55. Velupillai S, Mowery D, South BR, Kvist M, Dalianis H (2015) Recent advances in clinical natural language processing in support of semantic analysis. Yearb Med Inform 10:183-193

56. Cook BJ, Progovac AM, Chen P, Mullin B, Hou S, Baca-Garcia E (2016) Novel use of natural language processing (NLP) to predict suicidal ideation and psychiatric symptoms in a text-based mental health intervention in Madrid. Comput Math Methods Med. https ://doi.org/10.1155/2016/8708434

57. Berrouiguet $\mathrm{S}$, Baca-Garcia E, Brandt $\mathrm{S}$, Walter M, Courtet $\mathrm{P}$ (2016) Fundamentals for future mobile-health (mHealth): a systematic review of mobile phone and web-based text messaging in mental health. J Med Internet Res 18:e135

58. Berrouiguet S, Gravey M, Le Galudec M, Alavi Z, Walter M (2014) Post-acute crisis text messaging outreach for suicide prevention: a pilot study. Psychiatry Res 217:154-157

59. Barrett JA, Shetty H, Broadbent M, Cross S, Hotopf M, Stewart R, Lee W (2016) 'He left me a message on Facebook': comparing the risk profiles of self-harming patients who leave paper suicide notes with those who leave messages on new media. Br J Psychiatry Open 2:217-220

60. Franklin JC, Ribeiro JD, Fox KR et al (2017) Risk factors for suicidal thoughts and behaviors: a meta-analysis of 50 years of research. Psychol Bull 143:187-232

61. Free C, Phillips G, Felix L, Galli L, Patel V, Edwards P (2010) The effectiveness of $\mathrm{m}$-health technologies for improving health and health services: a systematic review protocol. BMC Res Notes 3:250

62. Zalsman G, Hawton K, Wasserman D et al (2016) Suicide prevention strategies revisited: 10-year systematic review. Lancet Psychiatry 3:646-659

63. Mann JJ, Apter A, Bertolote J et al (2005) Suicide prevention strategies: a systematic review. JAMA 294:2064-2074

64. Riblet NBV, Shiner B, Young-Xu Y, Watts BV (2017) Strategies to prevent death by suicide: meta-analysis of randomised controlled trials. Br J Psychiatry 210:396-402

65. World Health Organization (WHO) (2016) First WHO world suicide report. World Health Organization, Geneva 